\title{
BRCA1/2 NGS Somatic Testing in Clinical Practice: A Short Report
}

\author{
Francesco Pepe ${ }^{1,+}$, Pasquale Pisapia ${ }^{1,+}{ }^{+}$, Gianluca Russo ${ }^{1}\left(\mathbb{D}\right.$, Mariantonia Nacchio ${ }^{1}$, Pierlorenzo Pallante ${ }^{2}$, \\ Elena Vigliar ${ }^{1}\left(0\right.$, , Carmine De Angelis ${ }^{3}$, Luigi Insabato ${ }^{4} \oplus$, Claudio Bellevicine ${ }^{1}{ }^{\circledR}$, Sabino De Placido ${ }^{3}$, \\ Giancarlo Troncone ${ }^{1, *}$ and Umberto Malapelle ${ }^{1}[\mathbb{C}$
}

1 Department of Public Health, University of Naples Federico II, 80131 Naples, Italy; francesco.pepe4@unina.it (F.P.); pasquale.pisapia@unina.it (P.P.); gianlucar93@libero.it (G.R.); mariantonia.nacchio@unina.it (M.N.); elena.vigliar@unina.it (E.V.); claudio.bellevicine@unina.it (C.B.); umberto.malapelle@unina.it (U.M.)

2 Institute for Experimental Endocrinology and Oncology (IEOS) “G. Salvatore”, National Research Council (CNR), 80131 Naples, Italy; plpallante@gmail.com

3 Department of Clinical Medicine and Surgery, University of Naples Federico II, 80131 Naples, Italy; carmine.deangelis1@unina.it (C.D.A.); sabino.deplacido@unina.it (S.D.P.)

4 Department of Advanced Biomedical Sciences, School of Medicine, University of Naples Federico II, 80131 Naples, Italy; luigi.insabato@unina.it

* Correspondence: giancarlo.troncone@unina.it; Fax: +(011)-390-817-463-679

+ These Authors contributed equally as first authors.

Citation: Pepe, F.; Pisapia, P.; Russo, G.; Nacchio, M.; Pallante, P.; Vigliar, E.; De Angelis, C.; Insabato, L.; Bellevicine, C.; De Placido, S.; et al. BRCA1/2 NGS Somatic Testing in Clinical Practice: A Short Report. Genes 2021, 12, 1917. https:// doi.org/10.3390/genes12121917

Academic Editor: Michele Longo

Received: 16 November 2021

Accepted: 23 November 2021

Published: 28 November 2021

Publisher's Note: MDPI stays neutral with regard to jurisdictional claims in published maps and institutional affiliations.

Copyright: (C) 2021 by the authors. Licensee MDPI, Basel, Switzerland. This article is an open access article distributed under the terms and conditions of the Creative Commons Attribution (CC BY) license (https:// creativecommons.org/licenses/by/ $4.0 /)$.

\begin{abstract}
High-grade serous ovarian carcinoma (HGSOC) is the most common subtype of all ovarian carcinomas. HGSOC harboring $B R C A 1 / 2$ germline or somatic mutations are sensitive to the poly (adenosine diphosphate-ribose) polymerase inhibitors (PARPi). Therefore, detecting these mutations is crucial to identifying patients for PARPi-targeted treatment. In the clinical setting, next generation sequencing (NGS) has proven to be a reliable diagnostic approach BRCA1/2 molecular evaluation. Here, we review the results of our $B R C A 1 / 2$ NGS analysis obtained in a year and a half of diagnostic routine practice. $B R C A 1 / 2$ molecular NGS records of HGSOC patients were retrieved from our institutional archive covering the period from January 2020 to September 2021. NGS analysis was performed on the Ion S5 ${ }^{\mathrm{TM}}$ System (Thermo Fisher Scientific, Waltham, MA, USA) with the Oncomine $^{\mathrm{TM}}$ BRCA Research Assay panel (Thermo Fisher Scientific). Variants were classified as pathogenic or likely pathogenic according to the guidelines of the American College of Medical Genetics and Genomics by using the inspection of Evidence-based Network for the Interpretation of Germline Mutant Alleles (ENIGMA) and ClinVar (NCBI) databases. Sixty-five HGSOC patient samples were successfully analyzed. Overall, 11 (16.9\%) out of 65 cases harbored a pathogenic alteration in $B R C A 1 / 2$, in particular, six $B R C A 1$ and five $B R C A 2$ pathogenic variations. This study confirms the efficiency and high sensitivity of NGS analysis in detecting BRCA1/2 germline or somatic variations in patients with HGSOC.
\end{abstract}

Keywords: HGSOC; molecular pathology; BRCA1/2; PARPi; NGS

\section{Introduction}

Ovarian cancer (OC) is the eighth most common cancer type among women worldwide and the leading cause of death for gynecological malignancies [1,2]. Morphologically, OCs are generally classified into Type I and Type II tumors. Whereas the former are generally low-grade and genetically stable tumors, the latter, which predominantly harbor Tumor Protein P53 (TP53) and Cyclin E1 (CCNE1) gene alterations, are more aggressive and genetically unstable [3]. Among Type II ovarian tumors, high-grade serous ovarian carcinoma (HGSOC) is the most common subtype, accounting for about three quarters of OCs [4,5]. In 96\% of cases, HGSOCs carry TP53 somatic mutations. However, in $22 \%$ of 
cases, they are associated with BRCA1 DNA Repair Associated (BRCA1) or BRCA2 DNA Repair Associated (BRCA2) germline or somatic gene mutations [6].

Unfortunately, OC remains asymptomatic for several years and goes undetected until it is advanced. Indeed, in about 70\% of cases, the prognosis for HGSOC patients is rather bleak owing to late diagnosis [7]. Recently, considerable strides have been made in providing HGSOC patients with more effective personalized treatments, alongside traditional chemotherapy and antiangiogenic drugs.

Among the novel therapies, poly (adenosine diphosphate-ribose) polymerase inhibitors (PARPi) represent an important arrow in the oncologist's quiver [8]. Indeed, PARPi have been shown to dramatically improve the clinical outcomes of HGSOC patients harboring $B R C A 1 / 2$ germline or somatic mutations [9-12]. Accordingly, current international guidelines widely recommend $B R C A 1 / 2$ testing in all patients with non-mucinous OC, including those with HGSOC [13-15]. Next generation sequencing (NGS) is emerging as a useful and popular tool for $B R C A 1 / 2$ testing in clinical practice thanks to its high sensitivity, ease of use, cost-effectiveness, and short turnaround time. Not surprisingly, our Molecular Predictive Pathology Laboratory at the Department of Public Health of the University of Naples Federico II routinely employs NGS to assess clinically relevant biomarkers in different solid tumors $[16,17]$. The clinical significance of this striking technology is reflected in the fact that since 2020, the Divisions of Oncology and Gynecology at our Institution have fully embraced the use of NGS in their routine clinical practice to screen patients for $B R C A 1 / 2$ germline or somatic mutations.

Here, we review our $B R C A 1 / 2$ NGS molecular results obtained during the last a year and a half of diagnostic routine practice.

\section{Material and Methods}

Records from previous $B R C A 1 / 2$ molecular tests carried out on HGSOC patients from January 2020 to September 2021 were retrieved from our internal archive. In particular, DNA extraction was performed with the QiAmp Mini Kit (Qiagen, Hilden, Germany) according to the manufacturer's instructions. NGS analysis was performed on the Ion S5 $^{\mathrm{TM}}$ System (Thermo Fisher Scientific, Waltham, MA, USA) in combination with the Oncomine $^{\mathrm{TM}}$ BRCA Research Assay panel (Thermo Fisher Scientific). This panel covers all the coding sequences in $B R C A 1 / 2$ genes, including all coding splice and acceptor sites, with an average of $64 \mathrm{bp}$ extension into adjoining introns on Ion Torrent S5 (Thermo Fisher Scientific). In particular, library preparation and purification were manually performed according to the manufacturer's instructions. A total of $n=8$ amplified libraries were pooled together and diluted at $100 \mathrm{pM}$. Finally, template preparation and chip loading were performed automatically on the Ion Chef ${ }^{\mathrm{TM}}$ System (Thermo Fisher Scientific). Data inspection was carried out automatically by using the Ion Reporter Torrent Suite version 5.18.0.1 with a dedicated analysis workflow optimized for somatic annotation of BRCA1/2 alterations. In detail, a minimum coverage of $500 X$, a quality score $\geq 20$, and an allele mutation frequency of $\geq 5 \%$ were required to identify $B R C A 1 / 2$ mutations successfully. In addition, BAM files were visually inspected with the Golden Helix Genome Browser v.2.0.7 (Bozeman, MT, USA). Variant annotation was performed according to the Human Genome Variation Society nomenclature. Variants were classified as pathogenic or likely pathogenic (collectively termed pathogenic) according to the American College of Medical Genetics and Genomics (ACMG) recommendations by using the inspection of Evidencebased Network for the Interpretation of Germline Mutant Alleles (ENIGMA) and ClinVar (NCBI) databases.

\section{Results}

Overall, our in-house developed NGS workflow successfully analyzed a total of $n=65$ HGSOC histological samples. Patients' median age was 61.1 years (ranging from 25 to 91). All the histological samples were processed. In particular, the median value of neoplastic cell percentage was $59.7 \%$ (ranging from 10 to $90 \%$ ). Nucleic acid isolation and 
quantification yielded a median value of $39.7 \mathrm{ng} / \mu \mathrm{L}$ (ranging from 0.6 to $60.0 \mathrm{ng} / \mu \mathrm{L}$ ). As for the technical parameters, NGS analysis generated a median number of reads per sample of $1,382,380.2$ (ranging from 505.0 to $13,533,583.0$ ), a median number of read length of $106.5 \mathrm{bp}$ (ranging from 101 to $122 \mathrm{bp}$ ), a median number of mapped reads of 1,370,850.3 (ranging from 505.0 to $13,391,178.00$ ), a mean percentage of reads on target of $97.3 \%$ (ranging from 93.2 to $100 \%$ ), an average of reads per amplicon of 6754.5 (ranging from 2.9 to 76,092.00), and a uniformity of coverage of $97.5 \%$ (ranging from 91.5 to $100.0 \%$ ). Concerning the molecular results, whereas the vast majority of samples (54/65, 83.1\%) showed no clinically relevant alterations, 11 (16.9\%) out of 65 cases harbored a pathogenic alteration in BRCA1/2. In detail, six (54.5\%) out of 11 mutated cases displayed a BRCA1 pathogenic variation, whereas the remaining five $(45.5 \%)$ harbored a $B R C A 2$ pathogenic alteration. Among the detected alterations, six (54.5\%) were single nucleotide variants (SNVs) and five (45.5\%) were small deletions or insertions. Moreover, one of the detected alterations was found in a non-coding region. Results are summarized in Table 1.

Table 1. Results obtained in our series of 65 high-grade serous ovarian carcinomas.

\begin{tabular}{|c|c|c|c|c|c|c|c|c|c|c|c|}
\hline Patient & Age & $\begin{array}{l}\text { Neoplastic } \\
\text { Cells (\%) }\end{array}$ & $\begin{array}{c}\text { DNA } \\
\text { Concentration } \\
(\mathrm{ng} / \mu \mathrm{L})\end{array}$ & Reads & $\begin{array}{c}\text { Mapped } \\
\text { Reads }\end{array}$ & $\begin{array}{c}\text { Percent } \\
\text { Read on } \\
\text { Target (\%) }\end{array}$ & $\begin{array}{l}\text { Average } \\
\text { Reads per } \\
\text { Amplicon }\end{array}$ & $\begin{array}{c}\text { Uniformity } \\
\text { of } \\
\text { Amplicon } \\
\text { Coverage } \\
(\%)\end{array}$ & $\begin{array}{c}\text { Mean } \\
\text { Read } \\
\text { Length } \\
\text { (bp) }\end{array}$ & $\begin{array}{c}\text { Molecular } \\
\text { Result }\end{array}$ & Gene \\
\hline 1 & 74 & 70.00 & 19.90 & $1,103,756.00$ & $1,100,608.00$ & 98.15 & 3997.00 & 99.63 & 105.00 & WT & \\
\hline 2 & 55 & 70.00 & 60.00 & $447,320.00$ & $445,834.00$ & 99.87 & 1615.00 & 98.90 & 104.00 & WT & \\
\hline 3 & 51 & 60.00 & 41.00 & $990,443.00$ & $987,075.00$ & 99.87 & 2578.00 & 99.27 & 108.00 & WT & \\
\hline 4 & 60 & 70.00 & 5.79 & $999,781.00$ & $996,779.00$ & 99.08 & 3617.00 & 98.53 & 104.00 & WT & \\
\hline 5 & 42 & 70.00 & 60.00 & $1,225,736.00$ & $1,221,759.00$ & 99.04 & 4433.00 & 99.63 & 105.00 & p.R1495M & $B R C A 1$ \\
\hline 6 & 66 & 70.00 & 2.41 & $940,118.00$ & $937,071.00$ & 98.71 & 3388.00 & 97.70 & 101.00 & p.Q534X & $B R C A 1$ \\
\hline 7 & 69 & 70.00 & 25.40 & $1,134,001.00$ & $1,129,619.00$ & 98.79 & 4088.00 & 98.27 & 104.00 & WT & \\
\hline 8 & 91 & 80.00 & 60.00 & $1,107,249.00$ & $1,105,435.00$ & 99.09 & 4012.00 & 98.90 & 105.00 & WT & \\
\hline 9 & 72 & 70.00 & 60.00 & $978,740.00$ & $977,513.00$ & 98.93 & 3542.00 & 96.55 & 104.00 & p.K830PfsTer18 & $B R C A 1$ \\
\hline 10 & 66 & 70.00 & 60.00 & $1,015,943.00$ & $1,014,574.00$ & 99.33 & 3691.00 & 99.27 & 107.00 & WT & \\
\hline 11 & 53 & 70.00 & 38.90 & $529,337.00$ & $528,001.00$ & 98.76 & 1910.00 & 99.63 & 106.00 & WT & \\
\hline 12 & 71 & 50.00 & 25.30 & $1,111,471.00$ & $1,109,964.00$ & 99.28 & 4036.00 & 99.27 & 107.00 & WT & \\
\hline 13 & 63 & 50.00 & 6.19 & $1,091,731.00$ & $1,090,470.00$ & 99.32 & 3967.00 & 98.53 & 106.00 & WT & \\
\hline 14 & 61 & 70.00 & 60.00 & $1,120,367.00$ & $1,118,600.00$ & 99.15 & 4063.00 & 98.90 & 112.00 & WT & \\
\hline 15 & 61 & 60.00 & 53.00 & $1,140,727.00$ & $1,139,018.00$ & 99.06 & 4133.00 & 98.99 & 110.00 & WT & \\
\hline 16 & 25 & 50.00 & 60.00 & $1,052,429.00$ & $1,051,081.00$ & 99.06 & 3814.00 & 98.90 & 109.00 & WT & \\
\hline 17 & 64 & 60.00 & 17.30 & $538,487.00$ & $581,558.00$ & 99.05 & 2110.00 & 99.63 & 109.00 & WT & \\
\hline 18 & 68 & 80.00 & 60.00 & $574,298.00$ & $572,675.00$ & 98.75 & 2065.00 & 99.63 & 111.00 & WT & \\
\hline 19 & 52 & 30.00 & 6.38 & $626,317.00$ & $624,168.00$ & 98.66 & 2256.00 & 99.63 & 115.00 & WT & \\
\hline 20 & 69 & 70.00 & 60.00 & $667,821.00$ & $665,818.00$ & 98.91 & 2410.00 & 100.00 & 112.00 & WT & \\
\hline 21 & 58 & 70.00 & 11.20 & $585,530.00$ & $584,005.00$ & 98.92 & 2116.00 & 99.63 & 112.00 & $\begin{array}{c}\text { p.Q } \\
\text { 1756PfsTer74 }\end{array}$ & $B R C A 1$ \\
\hline 22 & 59 & 80.00 & 60.00 & $516,539.00$ & $514,737.00$ & 98.62 & 1861.00 & 100.00 & 115.00 & WT & \\
\hline 23 & 76 & 60.00 & 43.80 & $175,439.00$ & $175,084.00$ & 97.54 & 692.20 & 100.00 & 102.00 & WT & \\
\hline 24 & 76 & 70.00 & 57.00 & $195,477.00$ & $19,501.00$ & 98.68 & 704.90 & 100.00 & 102.00 & WT & \\
\hline 25 & 47 & 70.00 & 60.00 & $233,219.00$ & $232,620.00$ & 98.90 & 841.10 & 93.84 & 106.00 & WT & \\
\hline 26 & 69 & 90.00 & 60.00 & $222,662.00$ & $222,066.00$ & 98.90 & 804.40 & 100.00 & 107.00 & $\begin{array}{l}\text { p.IVS2 } \\
1 G>A\end{array}$ & $B R C A 2$ \\
\hline 27 & 48 & 70.00 & 60.00 & $230,212.00$ & $229,629.00$ & 100.00 & 832.50 & 98.63 & 104.00 & WT & \\
\hline 28 & 52 & 70.00 & 60.00 & $215,102.00$ & $214,804.00$ & 99.00 & 778.90 & 100.00 & 105.00 & WT & \\
\hline 29 & 44 & 50.00 & 60.00 & $218,442.00$ & $217,974.00$ & 99.10 & 791.20 & 100.00 & 107.00 & WT & \\
\hline 30 & 57 & 60.00 & 60.00 & $748,780.00$ & $746,568.00$ & 98.08 & 2682.00 & 100.00 & 106.00 & WT & \\
\hline 31 & 45 & 50.00 & 32.20 & $633,164.00$ & $631,252.00$ & 98.12 & 2269.00 & 98.90 & 103.00 & p.N319KfsTer8) & $B R C A 2$ \\
\hline 32 & 73 & 80.00 & 60.00 & $754,043.00$ & $702,880.00$ & 98.75 & 2542.00 & 100.00 & 105.00 & WT & \\
\hline 33 & 63 & 60.00 & 60.00 & $808,451.00$ & $806,608.00$ & 98.57 & 2913.00 & 100.00 & 107.00 & WT & \\
\hline 34 & 67 & 70.00 & 33.70 & $482,605.00$ & $481,960.00$ & 97.97 & 1727.00 & 96.30 & 103.00 & WT & \\
\hline 35 & 39 & 80.00 & 51.00 & $932,611.00$ & $931,119.00$ & 97.67 & 3331.00 & 99.27 & 102.00 & WT & \\
\hline 36 & 51 & 50.00 & 53.00 & $1,119,066.00$ & $1,116,901.00$ & 98.26 & 4020.00 & 100.00 & 105.00 & WT & \\
\hline
\end{tabular}


Table 1. Cont.

\begin{tabular}{|c|c|c|c|c|c|c|c|c|c|c|c|}
\hline Patient & Age & $\begin{array}{l}\text { Neoplastic } \\
\text { Cells (\%) }\end{array}$ & $\begin{array}{c}\text { DNA } \\
\text { Concentration } \\
(\mathrm{ng} / \mu \mathrm{L})\end{array}$ & Reads & $\begin{array}{c}\text { Mapped } \\
\text { Reads }\end{array}$ & $\begin{array}{c}\text { Percent } \\
\text { Read on } \\
\text { Target (\%) }\end{array}$ & $\begin{array}{l}\text { Average } \\
\text { Reads per } \\
\text { Amplicon }\end{array}$ & $\begin{array}{c}\text { Uniformity } \\
\text { of } \\
\text { Amplicon } \\
\text { Coverage } \\
(\%)\end{array}$ & $\begin{array}{c}\text { Mean } \\
\text { Read } \\
\text { Length } \\
\text { (bp) }\end{array}$ & $\begin{array}{c}\text { Molecular } \\
\text { Result }\end{array}$ & Gene \\
\hline 37 & 66 & 70.00 & 7.15 & $1,020,993.00$ & $1,019,060.00$ & 98.89 & 3691.00 & 100.00 & 102.00 & p.L1072Ter) & $B R C A 2$ \\
\hline 38 & 56 & 60.00 & 60.00 & $992,136.00$ & $990,635.00$ & 98.49 & 3574.00 & 100.00 & 102.00 & WT & \\
\hline 39 & 57 & 70.00 & 60.00 & $1,952,836.00$ & $1,949,593.00$ & 98.64 & 7045.00 & 99.63 & 106.00 & p.T1378Ter & $B R C A 2$ \\
\hline 40 & 77 & 70.00 & 60.00 & $1,584,808.00$ & $1,582,139.00$ & 98.47 & 5707.00 & 99.27 & 103.00 & WT & \\
\hline 41 & 70 & 20.00 & 13.80 & $689,251.00$ & $687,985.00$ & 95.00 & 3914.00 & 94.61 & 104.00 & WT & \\
\hline 42 & 60 & 50.00 & 60.00 & $668,595.00$ & $667,463.00$ & 94.00 & 3757.00 & 94.61 & 105.00 & WT & \\
\hline 43 & 40 & 50.00 & 60.00 & $675,510.00$ & $674,213.00$ & 95.64 & 3861.00 & 95.21 & 104.00 & WT & \\
\hline 44 & 70 & 50.00 & 22.20 & 505.00 & 505.00 & 97.03 & 2.90 & 91.57 & 105.00 & RIP & \\
\hline 45 & 64 & 50.00 & 10.70 & $683,922.00$ & $682,904.00$ & 93.36 & 3815.00 & 95.21 & 102.00 & WT & \\
\hline 46 & 52 & 10.00 & 51.00 & $619,053.00$ & $617,877.00$ & 94.31 & 3489.00 & 94.01 & 103.00 & WT & \\
\hline 47 & 81 & 60.00 & 30.30 & $472,447.00$ & $470,375.00$ & 94.42 & 2654.00 & 93.41 & 109.00 & WT & \\
\hline 48 & 67 & 70.00 & 60.00 & $204,918.00$ & $204,318.00$ & 93.72 & 1147.00 & 94.01 & 111.00 & WT & \\
\hline 49 & 33 & 60.00 & 60.00 & $574,974.00$ & $572,585.00$ & 93.02 & 3189.00 & 95.21 & 109.00 & p.Q1811Ter & $B R C A 1$ \\
\hline 50 & 72 & 70.00 & 60.00 & $13,533,583.00$ & $13,391,178.00$ & 94.89 & $76,092.00$ & 95.81 & 105.00 & WT & \\
\hline 51 & 74 & 40.00 & 5.40 & $9,481,551.00$ & $9,408,339.00$ & 94.13 & $53,031.00$ & 95.21 & 104.00 & WT & \\
\hline 52 & 49 & 50.00 & 19.70 & $12,876,898.00$ & $12,766,795.00$ & 94.17 & $71,989.00$ & 96.41 & 103.00 & WT & \\
\hline 53 & 48 & 60.00 & 60.00 & $13,327,661.00$ & $13,176,126.00$ & 94.45 & $74,523.00$ & 96.41 & 106.00 & WT & \\
\hline 54 & 73 & 60.00 & 60.00 & 1521.00 & 1503.00 & 93.35 & 8.40 & 93.53 & 103.00 & WT & \\
\hline 55 & 53 & 60.00 & 18.80 & $592,625.00$ & $590,434.00$ & 94.04 & 3325.00 & 96.41 & 122.00 & p.Q2157IfsTer18 & $B R C A 2$ \\
\hline 56 & 76 & 20.00 & 0.60 & $459,548.00$ & $458,573.00$ & 96.02 & 2637.00 & 96.41 & 106.00 & WT & \\
\hline 57 & 68 & 80.00 & 60.00 & $442,179.00$ & $440,884.00$ & 94.76 & 2502.00 & 95.81 & 108.00 & WT & \\
\hline 58 & 62 & 50.00 & 8.50 & $382,324.00$ & $381,454.00$ & 96.15 & 2196.00 & 95.81 & 106.00 & WT & \\
\hline 59 & 54 & 40.00 & 11.60 & $433,234.00$ & $431,971.00$ & 95.86 & 2480.00 & 95.25 & 111.00 & p.C61G & $B R C A 1$ \\
\hline 60 & 66 & 70.00 & 47.00 & $407,607.00$ & $406,640.00$ & 95.03 & 2314.00 & 95.03 & 106.00 & WT & \\
\hline 61 & 63 & 20.00 & 3.40 & $276,753.00$ & $275,901.00$ & 96.05 & 1587.00 & 95.21 & 111.00 & WT & \\
\hline 62 & 62 & 70.00 & 37.80 & $280,573.00$ & $279,771.00$ & 96.01 & 1609.00 & 95.21 & 104.00 & WT & \\
\hline 63 & 64 & 70.00 & 16.00 & $227,648.00$ & $228,989.00$ & 95.27 & 1295.00 & 94.01 & 107.00 & WT & \\
\hline 64 & 74 & 40.00 & 4.14 & $275,446.00$ & $274,321.00$ & 95.03 & 1561.00 & 94.01 & 111.00 & WT & \\
\hline 65 & 61 & 10.00 & 6.90 & $248,198.00$ & $247,411.00$ & 95.53 & 1415.00 & 95.21 & 112.00 & WT & \\
\hline
\end{tabular}

\section{Discussion}

The assessment of BRCA1/2 molecular status has become part of the standard of care in the management of patients with HGSOC. Much progress has been made in the field of precision medicine against this type of cancer, which is responsible for over $60 \%$ of ovarian cancer-related deaths. A case in point is the development and clinical implementation of PARPi, which have been shown to improve the survival as well as quality of life patients affected by HGSOC. Thus, fast and reliable genetic screening for BRCA1/2 germline or somatic mutations has become of paramount importance to identify patients who would most likely benefit from these therapeutic agents.

This study highlights the high sensitivity, even in cases with a low neoplastic cells content, of NGS technology in detecting BRCA1/2 pathogenic mutations in patients with HGSOC. In particular, our in-house developed NGS platform and workflow successfully evaluated the BRCA1/2 status in a total of 65 HGSOCs. In line with previous published studies [6], our molecular analysis confirmed the presence of $B R C A 1 / 2$ pathogenic alterations in a substantial percentage $(16.9 \%)$ of HGSOC patients. This strongly suggests the need to integrate $B R C A 1 / 2$ testing into routine clinical practice (Figure 1). In this setting, NGS, a robust and highly sensitive technology, provides clinicians with the opportunity to comprehensively evaluate $B R C A 1 / 2$ molecular status in both HGSOC and other types of cancer [18]. For over a decade now, NGS systems have revolutionized diagnostic practice by improving the success rates of molecular tests even when the diagnostic material is scant. Such paradigm-shifting technology has therefore laid the basis not only for an improved biomarker testing landscape but also for the development of multiple biomarker-based 
therapeutic strategies. With regard to $B R C A$ genetic testing, our Predictive Molecular Pathology Laboratory at Federico II University Hospital regularly partakes in a national project to sensitize oncologists, primary pathologists, and molecular laboratories to the importance of $B R C A 1 / 2$ molecular analysis for HGSOC patients. To this end, the project has developed a dedicated website (http:/ / www.brcafastnet.it, last access 16 Novermber 2021) able to oversee all clinical data exchange and shipment of biological material to all institutions involved in the project. Currently, a plethora of NGS panels are commercially available for $B R C A 1 / 2$ molecular testing. Despite the high heterogeneity in terms of technical approaches (e.g., chemistry, library preparations, and sequencing analysis) and data analysis (e.g., metrics and bioinformatics pipelines), several studies have long demonstrated a high degree of concordance among the variant cells [18].

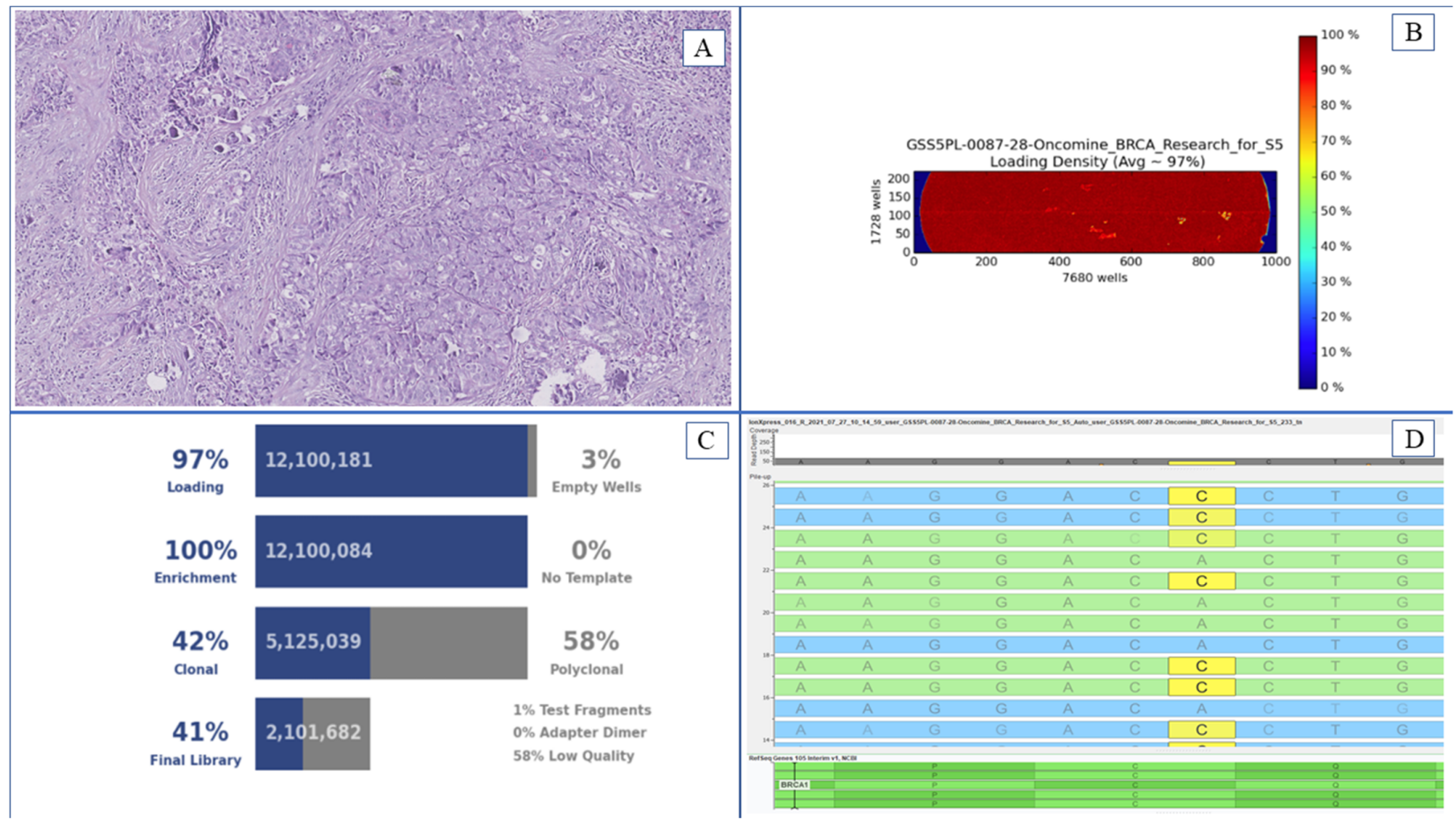

Figure 1. BRCA1/2 molecular evaluation with NGS approach: an exemplificative case. This Figure also shows a neoplastic area for DNA extraction (A), loading density (B), and technical quality parameters (C) of a NGS run on an Ion Torrent S5 TM platform (Thermo Fisher Scientifics). Box (D) shows a BRCA1 p.C61G point mutation with an integrated genetics viewer.

In conclusion, we have presented a referral laboratory experience on $B R C A 1 / 2$ molecular analysis in unselected HGSOC patients from our diagnostic routine activity to highlight the crucial role of NGS analysis in the correct management of these patients. Further studies involving a larger gene panel are needed to investigate other promising gene alterations involved in homologous recombinant deficiency (HRD), which may expand the subset of HGSOC patients suitable for PARPi treatment.

Author Contributions: Conceptualization, F.P., P.P. (Pasquale Pisapia), G.T., U.M.; Methodology, all authors; Software, all authors; Validation, all authors; Formal Analysis, all authors; Investigation, all authors; Data Curation, all authors; Writing-Original Draft Preparation, F.P., P.P. (Pasquale Pisapia), U.M.; Writing—Review \& Editing, all authors; Visualization, all authors; Supervision, G.T., U.M.; Project Administration, G.T., U.M.; Funding Acquisition, G.T. All authors have read and agreed to the published version of the manuscript. 
Funding: 1. Monitoraggio ambientale, studio ed approfondimento della salute della popolazione residente in aree a rischio-In attuazione della D.G.R. Campania n.180/2019 to G.T. 2. POR Campania FESR 2014-2020 Progetto “Sviluppo di Approcci Terapeutici Innovativi per patologie Neoplastiche resistenti ai trattamenti-SATIN" to G.T.

Institutional Review Board Statement: Written informed consent was obtained from all patients and documented in accordance with the general authorization to process personal data for scientific research purposes from “The Italian Data Protection Authority" (http:/ / www.garanteprivacy.it/web/ guest/home/docweb/- / docwebdisplay/export/2485392, accessed on 22 November 2021). All information regarding human material was managed using anonymous numerical codes, and all samples were handled in compliance with the Helsinki Declaration (https: / / www.wma.net/ fr / news-post/enmatiere-de-transfert-des-taches-la-securite-des-patients-et-la-qualite-des-soins-devraient-etre-prim ordiales /, accessed on 22 November 2021). According to the aforementioned national guidelines, the double-blinded study did not require an Ethical Committee approval since it did not affect the clinical management of the involved patients' samples.

Informed Consent Statement: Informed consent was obtained from all subjects involved in the study.

Data Availability Statement: The data presented in this study are available on request from the corresponding author.

Acknowledgments: We thank Paola Merolla for editing the manuscript.

Conflicts of Interest: Umberto Malapelle has received personal fees (as consultant and/or speaker bureau) from Boehringer Ingelheim, Roche, MSD, Amgen, Thermo Fisher Scientifics, Eli Lilly, Diaceutics, GSK, Merck and AstraZeneca, unrelated to the current work. Giancarlo Troncone reports personal fees (as speaker bureau or advisor) from Roche, MSD, Pfizer, Boehringer Ingelheim, Eli Lilly, BMS, GSK, Menarini, AstraZeneca, Amgen and Bayer, unrelated to the current work. Carmine De Angelis has received personal fees (as consultant and/or speaker bureau) from Roche, Eli Lilly, GSK, Novartis, Pfizer and AstraZeneca, unrelated to the current work. Sabino De Placido has received personal fees (as consultant and/or speaker bureau) from Novartis, Roche, Celgene, AstraZeneca, Pfizer, Lilly, Eisai, Seagen, Daiichi Sankyo, Clovis, GSK, MSD, unrelated to the current work. The other authors have nothing to disclose.

\section{References}

1. Siegel, R.L.; Miller, K.D.; Fuchs, H.E.; Jemal, A. Cancer Statistics, 2021. CA Cancer J. Clin. 2021, 71, 7-33. [CrossRef] [PubMed]

2. Torre, L.A.; Trabert, B.; DeSantis, C.E.; Miller, K.D.; Samimi, G.; Runowicz, C.D.; Gaudet, M.M.; Jemal, A.; Siegel, R.L. Ovarian cancer statistics, 2018. CA Cancer J. Clin. 2018, 68, 284-296. [CrossRef] [PubMed]

3. Kurman, R.J.; Shih, I.M. The Dualistic Model of Ovarian Carcinogenesis: Revisited, Revised, and Expanded. Am. J. Pathol. 2016, 186, 733-747. [CrossRef] [PubMed]

4. Labidi-Galy, S.I.; Papp, E.; Hallberg, D.; Niknafs, N.; Adleff, V.; Noe, M.; Bhattacharya, R.; Novak, M.; Jones, S.; Phallen, J.; et al. High grade serous ovarian carcinomas originate in the fallopian tube. Nat. Commun. 2017, 8, 1093. [CrossRef] [PubMed]

5. Prat, J.; FIGO Committee on Gynecologic Oncology. Staging classification for cancer of the ovary, fallopian tube, and peritoneum. Int. J. Gynaecol. Obstet. 2014, 124, 1-5. [CrossRef] [PubMed]

6. Cancer Genome Atlas Research Network. Integrated genomic analyses of ovarian carcinoma. Nature 2011, 474, 609-615. [CrossRef] [PubMed]

7. Lisio, M.-A.; Fu, L.; Goyeneche, A.; Gao, Z.-H.; Telleria, C. High-Grade Serous Ovarian Cancer: Basic Sciences, Clinical and Therapeutic Standpoints. Int. J. Mol. Sci. 2019, 20, 952. [CrossRef] [PubMed]

8. Valabrega, G.; Scotto, G.; Tuninetti, V.; Pani, A.; Scaglione, F. Differences in PARP Inhibitors for the Treatment of Ovarian Cancer: Mechanisms of Action, Pharmacology, Safety, and Efficacy. Int. J. Mol. Sci. 2021, 22, 4203. [CrossRef] [PubMed]

9. Ray-Coquard, I.; Pautier, P.; Pignata, S.; Pérol, D.; González-Martín, A.; Berger, R.; Fujiwara, K.; Vergote, I.; Colombo, N.; Mäenpää, J.; et al. Olaparib plus Bevacizumab as First-Line Maintenance in Ovarian Cancer. N. Engl. J. Med. 2019, 381, 2416-2428. [CrossRef] [PubMed]

10. González-Martín, A.; Pothuri, B.; Vergote, I.; DePont Christensen, R.; Graybill, W.; Mirza, M.R.; McCormick, C.; Lorusso, D.; Hoskins, P.; Freyer, G.; et al. PRIMA/ENGOT-OV26/GOG-3012 Investigators. Niraparib in Patients with Newly Diagnosed Advanced Ovarian Cancer. N. Engl. J. Med. 2019, 381, 2391-2402. [CrossRef] [PubMed]

11. Moore, K.; Colombo, N.; Scambia, G.; Kim, B.-G.; Oaknin, A.; Friedlander, M.; Lisyanskaya, A.; Floquet, A.; Leary, A.; Sonke, G.S.; et al. Maintenance Olaparib in Patients with Newly Diagnosed Advanced Ovarian Cancer. N. Engl. J. Med. 2018, 379, $2495-2505$. [CrossRef] [PubMed] 
12. Swisher, E.M.; Lin, K.K.; Oza, A.; Scott, C.L.; Giordano, H.; Sun, J.; E Konecny, G.; Coleman, R.L.; Tinker, A.V.; O’Malley, D.M.; et al. Rucaparib in relapsed, platinum-sensitive high-grade ovarian carcinoma (ARIEL2 Part 1): An international, multicentre, open-label, phase 2 trial. Lancet Oncol. 2017, 18, 75-87. [CrossRef]

13. Konstantinopoulos, P.A.; Norquist, B.; Lacchetti, C.; Armstrong, D.; Grisham, R.N.; Goodfellow, P.J.; Kohn, E.C.; Levine, D.A.; Liu, J.F.; Lu, K.H.; et al. Germline and Somatic Tumor Testing in Epithelial Ovarian Cancer: ASCO Guideline. J. Clin. Oncol. 2020, 38, 1222-1245. [CrossRef] [PubMed]

14. Colombo, N.; Sessa, C.; du Bois, A.; Ledermann, J.; McCluggage, W.G.; McNeish, I.; Morice, P.; Pignata, S.; Ray-Coquard, I.; Vergote, I.; et al. ESMO-ESGO Ovarian Cancer Consensus Conference Working Group. ESMO-ESGO consensus conference recommendations on ovarian cancer: Pathology and molecular biology, early and advanced stages, borderline tumours and recurrent disease. Ann Oncol. 2019, 30, 672-705. [CrossRef] [PubMed]

15. Gori, S.; Barberis, M.; Bella, M.A.; Buttitta, F.; Capoluongo, E.; Carrera, P.; Colombo, N.; Cortesi, L.; Genuardi, M.; Gion, M.; et al. Recommendations for the implementation of BRCA testing in ovarian cancer patients and their relatives. Crit. Rev. Oncol. Hematol. 2019, 140, 67-72. [CrossRef] [PubMed]

16. Malapelle, U.; Mayo de-Las-Casas, C.; Rocco, D.; Garzon, M.; Pisapia, P.; Jordana-Ariza, N.; Russo, M.; Sgariglia, R.; De Luca, C.; Pepe, F.; et al. Development of a gene panel for next-generation sequencing of clinically relevant mutations in cell-free DNA from cancer patients. Br. J. Cancer 2017, 116, 802-810. [CrossRef] [PubMed]

17. De Luca, C.; Pepe, F.; Iaccarino, A.; Pisapia, P.; Righi, L.; Listì, A.; Greco, L.; Gragnano, G.; Campione, S.; De Dominicis, G.; et al. RNA-Based Assay for Next-Generation Sequencing of Clinically Relevant Gene Fusions in Non-Small Cell Lung Cancer. Cancers 2021, 13, 139. [CrossRef] [PubMed]

18. Fumagalli, C.; Guerini-Rocco, E.; Buttitta, F.; Iapicca, P.; You, W.; Mauri, M.; Felicioni, L.; Troncone, G.; Malapelle, U.; Scarpa, A.; et al. Reliability and reproducibility among different platforms for tumour BRCA testing in ovarian cancer: A study of the Italian NGS Network. J. Clin. Pathol. 2020, 74, 668-672. [CrossRef] [PubMed] 